\title{
A TRAJETÓRIA DA PARTICIPAÇÃO PÚBLICA EM MATÉRIA URBANO AMBIENTAL NO SISTEMA JURÍDICO BRASILEIRO
}

THE TRAJECTORY OF PUBLIC PARTICIPATION IN URBAN-ENVIRONMENTAL MATTERS IN THE BRAZILIAN LEGAL SYSTEM

DANIELLA MARIA DOS SANTOS DIAS ${ }^{1}$

Maria Claudia Bentes Albuquerque ${ }^{2}$

\section{Resumo}

Este artigo revisita o processo de afirmação histórica do direito à participação pública em matéria urbano ambiental no Brasil. Parte-se de pesquisa exploratória sobre a evolução da cidadania no Brasil Republicano para compreender, atualmente, o direito à participação democrática na gestão de cidades. O objetivo é analisar os fundamentos jurídico-políticos para o exercício da participação pública em questões com interface urbanística e ambiental. Visa-se responder o seguinte problema: em que medida o sistema jurídico brasileiro encontra-se estruturado para propiciar a participação pública em deliberações de caráter urbano ambiental? O estudo qualitativo tem abordagem analítico-descritiva e contou com a aplicação de pesquisa bibliográfica e documental para a coleta de materiais teórico-conceituais e normativos. A organização e análise dos dados foram realizadas pela técnica do mapeamento cognitivo. Como resultado, verificou-se que, apesar dos avanços ocorridos no sistema jurídico brasileiro após a Constituição de 1988, ainda é necessário promover a criação de mecanismos institucionais e medidas democráticas inovadoras para ampliar o exercício dos direitos à informação e à participação pública. Conclui-se que a inexistência de critérios objetivos para avaliação da efetividade do direito à participação pública desafia a proteção do meio ambiente e a gestão de cidades.

\footnotetext{
1 Professora Titular da Universidade Federal do Pará. Professora do Instituto de Ciências Jurídicas e do Programa de Pós-Graduação em Direito da Universidade Federal do Pará. Doutora em Direito pela Universidade Federal de Pernambuco (2001). Realizou investigação Pós-Doutoral na Universidade Carlos III de Madri na Espanha, junto ao Departamento de Direito Público Comparado e ao Instituto Pascual Madoz. Atualmente é Promotora de Justiça do Ministério Público do Estado do Pará e Professora da Universidade Federal do Pará (Graduação e Pós-Graduação). Instituição: Universidade Federal do Pará - UFPA, Pará. Brasil. E-mail: diasdaniella@gmail.com

2 Doutoranda em Direito pela UFPA, Mestre em Gestão de Recursos Naturais e Desenvolvimento Local na Amazônia pela UFPA. Advogada. Instituição: Universidade Federal do Pará - UFPA, Pará. Brasil. E-mail: mariaclaudiabentes@gmail.com
} 
Palavras-chave: Direitos humanos. Cidadania. Participação pública. Meio Ambiente. Cidade sustentável.

\section{Abstract}

This article revisits the process of historical affirmation of the right to public participation in urbanenvironmental matters in Brazil. It starts with exploratory research about the evolution of citizenship in Republican Brazil to understand, at present, the right to democratic participation in city management. The objective is to analyze the legal and political grounds for the exercise of public participation in issues with urban and environmental interface. It is intended to answer this following problem: to what extent is the Brazilian legal system structured to provide public participation in urban-environmental deliberations? The qualitative study has an analytical-descriptive approach and counted on the application of bibliographical and documentary research for the collection of theoretical-conceptual and normative materials. Data organization and analysis were performed using the cognitive mapping technique. As a result, it has been verified that, despite the advances made in the Brazilian legal system after the 1988 Constitution, it is still necessary to promote the creation of institutional mechanisms and innovative democratic measures to increase the exercise of the rights to information and public participation. It is concluded that the inexistence of objective criteria to evaluate the effectiveness of the right to public participation challenges the protection of the environment and city management.

Keywords: Human rights. Citizenship. Public participation. Environment. Sustainable city.

\section{Introdução}

A Constituição da República de 1988 representa um marco no processo de democratização do Brasil, uma vez que propiciou o fortalecimento da atuação do Poder Público e da coletividade em seus deveres solidários e comuns. Na Carta Magna, a proteção do meio ambiente é considerada um princípio que orienta a Ordem Econômica e que instrumenta a implementação de políticas públicas, funcionando como uma linha-mestra para a realização do princípio da dignidade humana.

A Lei n. 10.257/2001 (Estatuto da Cidade), ao conferir densidade aos artigos 21, XX, 182 e 183 da Constituição da República de 1988, que tratam da política de desenvolvimento urbano, fixou normas de ordem pública e interesse social sobre uso e ocupação do solo urbano, visando a promoção de igualdade, cidadania e melhoria da qualidade de vida. 
As limitações urbanísticas e ambientais ao exercício do direito de propriedade, enquanto conquistas que resultam do protagonismo de movimentos sociais engajados na luta por reforma urbana, objetivam assegurar a realização da função social e ecológica da terra, bem como a função social da cidade, visando o bem-estar coletivo e a proteção do meio ambiente, consubstanciados no direito transindividual à cidade sustentável que foi introduzido no Brasil pelo Estatuto da Cidade.

Para assegurar o controle social e o pleno exercício da cidadania, a Lei n. 10.257/2001 determina que os gestores públicos promovam, obrigatoriamente, a participação democrática na gestão da cidade, o que imprescinde de efetivo acesso à informação e à justiça em matéria urbanoambiental. Nesse sentido, a promoção do direito material e procedimental à participação pública surge como condição de legitimidade das práticas e decisões administrativas, no sentido de uma cidadania urbana e ambiental mais responsável.

Não obstante a conquista que a Carta Magna e o Estatuto da Cidade representam, do ponto de vista das lutas sociais por cidadania política ocorridas ao longo do século XX, impulsionadas sobretudo pelo Fórum Nacional pela Reforma Urbana nas décadas de 1980 e 1990, a efetivação do direito à participação pública para gestão democrática da cidade e proteção do meio ambiente enfrenta o desafio da correlação de forças em âmbito local, em virtude das assimetrias de poder que se sobrepõem sobre os espaços urbanos, historicamente marcados por exclusão social e profundas desigualdades, que colocam em risco os direitos humanos como um todo.

Tendo em vista este contexto, o processo de afirmação histórica do direito à participação pública em matéria urbanoambiental no Brasil. Parte-se de pesquisa exploratória sobre a evolução da cidadania no Brasil Republicano para compreender, atualmente, o direito à participação democrática na gestão de cidades. O objetivo consiste em analisar os fundamentos jurídico-políticos para o exercício da participação pública em questões com interface urbanística e ambiental. Visa-se responder o seguinte problema: em que medida o sistema jurídico brasileiro encontra-se estruturado para propiciar a participação pública em deliberações de caráter urbanoambiental?

Quanto à metodologia, trata-se de um estudo dogmático inserido no campo do Direito, no qual utiliza-se método dedutivo e abordagem qualitativa, de cunho analítico-descritivo e exploratório. Para a coleta de materiais teórico-conceituais que embasaram a revisão de literatura narrativa, foi aplicada a técnica da pesquisa bibliográfica, a partir de busca pelas palavras-chave "direitos humanos", "cidadania", "participação pública", "meio ambiente" e "cidade sustentável".

A procura foi realizada entre os meses de agosto de 2017 e agosto de 2018, em diversos bancos de dados (sítios eletrônicos de instituições públicas e privadas, anais de eventos científicos, biblioteca particular da pesquisadora, plataforma de periódicos da Coordenação de 
Aperfeiçoamento de Pessoal de Nível Superior - CAPES etc.), visando mapear sem adoção de critério sistemático e exaustivo estudos sobre o tema investigado.

A pesquisa documental foi realizada no mesmo período, aplicando-se busca pelos parâmetros "participação" e "gestão de cidade" em sítios eletrônicos de pesquisa livre, objetivando a coleta de materiais normativos examinados neste artigo, em especial a Constituição da República de 1988 e a Lei n. 10.257/2001 (Estatuto da Cidade).

Como resultado da pesquisa bibliográfica, foram encontradas diversas obras jurídicas e não jurídicas (artigos, livros, coletâneas, teses e dissertações) sobre o tema da participação pública na tutela do meio ambiente e na gestão de cidades, com variados níveis de qualidade, abrangência e contribuição acadêmica.

Os estudos foram selecionados pelo critério de qualidade e pertinência temática com a pesquisa, a partir de leitura do título, do resumo e das palavras-chave. Após, foram organizados e analisados pela técnica do mapeamento cognitivo, de modo a evidenciar, por meio de gráficos gerados com recursos da plataforma Windows (Word), o estado da arte sobre o tema investigado, bem como relações, contradições, lacunas e inconsistências verificadas na literatura.

A primeira seção é dedicada a uma sucinta investigação sobre o processo de formação da cidadania política no Brasil, com enfoque na sua fase republicana. Na segunda seção discute-se a relação entre direitos humanos, cidadania, proteção do meio ambiente e gestão de cidades, com ênfase na análise das lutas sociais e conquistas urbanas ocorridas nos planos nacional e internacional, a partir do século XX, que contribuíram para uma aproximação entre direitos humanos e proteção ambiental.

Por fim, analisa-se sob uma perspectiva institucional e lógica dedutiva, o arcabouço normativo brasileiro atinente à garantia e à promoção do direito à participação pública em matéria urbanoambiental, partindo dos fundamentos encartados na Constituição da República de 1988 e no Estatuto da Cidade, que funcionam como pilares e motores das políticas ambiental e urbana brasileiras.

\section{Da cidadania diferenciada à cidadania urbana no Brasil Republicano}

O processo de formação da cidadania política no Brasil é fortemente marcado por exclusão da maioria dos brasileiros, da fase colonial à republicana. Critérios socioeconômicos, como gênero, idade, dependência doméstica, riqueza e educação, e qualificação burocrática dos eleitores foram utilizados durante séculos como argumentos jurídicos para afastar a maior parte dos brasileiros da 
cidadania política e, assim, garantir manobras eleitorais favoráveis aos interesses dominantes (HOLSTON, 2013, p. 120-121).

Na fase colonial, as restrições estabelecidas por força de lei favoreciam apenas os interesses dos chamados "homens bons" ou "homens de posses", com exclusão do restante dos cidadãos brasileiros, como por exemplo mulheres, escravos, estrangeiros, membros de ordens religiosas e pessoas de "poucas posses".

A Constituição Imperial estabeleceu os alicerces da cidadania diferenciada, modelo adotado em quase todo o século XIX e no século XX, o qual foi caracterizado por mecanismos de distinção entre pessoas livres e escravas, entre cidadãos e estrangeiros, que produziram restrições de capacidade e exclusão de direitos políticos.

As estratégias de cidadania diferenciada foram utilizadas por liberais para propiciar a negação de direitos políticos às classes mais baixas, contrariando os interesses prevalentes de conservadores que preferiam o controle dos seus empregados por meio do voto, para assegurar domínio político local (HOLSTON, 2013, p. 130).

Na fase correspondente à Primeira República foram instituídas as eleições diretas e estabelecido que o voto seria facultativo. As categorias votante e eleitor foram reunidas, entretanto mantiveram-se os mecanismos de cidadania diferenciada em prol do controle e da alienação social. Esse acontecimento evidencia que o liberalismo brasileiro não assimilou a participação popular na política (CARVALHO, 2014, p. 155).

Após 1930, com a organização da nova classe de trabalhadores assalariados urbanos, inúmeras reformas foram promovidas no sistema jurídico brasileiro, como a criação da Justiça Eleitoral, a redução da idade para votar, a retomada do registro obrigatório e a extensão do direito de votar às mulheres (HOLSTON, 2013, p. 144-145). Na democracia do Estado Novo, os direitos sociais quase não apresentaram evolução (CARVALHO, 2014, p. 156). O período apresenta, no entanto, um primeiro passo dado no sentido da promoção da participação popular na política brasileira (CARVALHO, 2014, p. 148), ainda que sob incipiente processo democrático.

Apesar das mudanças ocorridas no início do século XX, as eleições diretas somente foram retomadas na década de 1980, durante o processo de redemocratização do país, uma vez que o regime militar (1964-1985) suprimia liberdades e controlava a participação popular por meio da repressão política e da manipulação eleitoral, causando despolitização e limitação ao exercício da democracia (HOLSTON, 2013, p. 148). 
O modelo de cidadania iniciado na fase colonial e mantido na Primeira República foi replicado na fase republicana moderna, quando começou a surgir nas periferias urbanas um movimento de insurgência contra os critérios de diferenciação e a formulação desigual da cidadania.

Três fatores teriam alavancado profundas mudanças na cidadania brasileira nas seis décadas seguintes à Revolução de 1930, a dizer, o voto das mulheres, a democratização e, sobretudo, o processo de urbanização, pois os novos cidadãos, notadamente os trabalhadores urbanos, passaram a se opor ao histórico modelo de exclusão, a exigir direitos políticos e a demandar novas formas de participação democrática, fincando, assim, as bases de uma nova forma de cidadania: a cidadania urbana (HOLSTON, 2013, p. 149-150).

2 Direitos humanos, cidadania urbana e proteção do meio ambiente: uma luta convergente

A concepção de cidadania passou por diversas mudanças ao longo da história brasileira, tendo sido marcada na fase moderna por influências liberais, que concebem os direitos humanos como direitos individuais, privilegiando direitos civis e políticos, sob uma perspectiva restritiva, em detrimento de direitos coletivos, econômicos e sociais (SANTOS; CHAUÍ, 2013, p. 43).

No século XX, a dignidade humana passou a compor o discurso triunfante dos direitos humanos, em conformidade com os interesses de um colonialismo metamorfoseado e das políticas liberais ocidentais (SANTOS; CHAUÍ, 2013, p. 49), que excluíam grande parte da população mundial da condição de sujeito de direitos humanos.

No Brasil, a qualificação burocrática e restritiva de direitos políticos assegurou os interesses das classes dominantes. Com efeito, a concessão de direitos inerentes à cidadania às classes excluídas (analfabetos, pobres, mulheres, negros etc.) ocorreu segundo um projeto de desenvolvimento conveniente à garantia dos interesses dominantes (econômicos, sociais e políticos), o que acabou levando a questionamentos e críticas sobre o papel do Estado na efetivação dos direitos humanos, em especial dos direitos econômicos, sociais e culturais (DESC), cuja essência demanda uma mudança na natureza política da ação estatal (SANTOS; CHAUÍ, 2013, p. 66).

A história brasileira é assinalada por um processo de despolitização que limitou o exercício democrático da cidadania ativa na esfera pública, da fase colonial à republicana, mediante a manutenção de mecanismos institucionalizados de cidadania diferenciada que foram assegurados por agentes detentores de poder (estatais e não estatais) contra indivíduos e grupos sociais discriminados, em prejuízo ao desenvolvimento de direitos e deveres civis e à realização de justiça substantiva. 
Por outro lado, o mesmo cenário que produziu exclusões e profundas desigualdades tornouse palco de contraposição ao projeto liberal e ao seu modelo de desenvolvimento, notadamente em virtude da articulação em rede de trabalhadores e movimentos sociais urbanos com organizações não governamentais que passaram a reivindicar a efetivação dos direitos humanos de forma integral, perpassando por uma luta pelo direito ao meio ambiente sadio e equilibrado como condição necessária à realização da dignidade humana.

Os direitos ambientais surgiram, assim, no contexto de lutas democráticas por direitos humanos contra hegemônicos, provocando uma tensão com o direito ao desenvolvimento de matriz liberal (SANTOS; CHAUÍ, 2013, p. 96), que foi aumentada com o processo de internacionalização da proteção dos direitos humanos, a partir da Declaração Universal dos Direitos Humanos (1948).

A luta pela proteção dos direitos humanos acabou revelando pontos de convergência com a luta pela proteção do meio ambiente, na medida em que ambos visavam a melhoria das condições de vida e uma ampliação do direito à cidadania. O fortalecimento recíproco de ambas as lutas foi mais evidente nas áreas urbanas, onde a maioria da população brasileira passou a habitar como consequência dos processos de industrialização e urbanização experimentados pelo Brasil.

Foi a partir da segunda metade do século XX que problemas globais emergentes relacionados à qualidade ambiental começaram a fazer parte das pautas de discussões nacionais e internacionais sobre direitos humanos. O aumento da crise ecológica nos anos seguintes ao término da Segunda Guerra Mundial atraiu para o núcleo dos debates políticos globais preocupações com o esgotamento dos recursos naturais, colocando em evidência as repercussões da degradação ambiental sobre a vida humana.

A Conferência de Estocolmo (1972), realizada na Suécia, foi o primeiro grande evento promovido pela Organização das Nações Unidas (ONU) para discutir a relação entre questões ambientais e direitos humanos, sendo por isso considerada o marco da internacionalização da proteção ambiental. O histórico encontro resultou na elaboração da Declaração da Conferência das Nações Unidas sobre o Meio Ambiente Humano (1972), após a qual diversos Estados-partes, inclusive o Brasil, passaram a assumir progressivamente compromissos de cooperação internacional voltados à proteção do meio ambiente.

Em 1992, a elaboração da Agenda 21 Global - instrumento de planejamento participativo para o desenvolvimento sustentável - pelos Estados participantes da Conferência Internacional da Organização das Nações Unidas sobre Meio Ambiente e Desenvolvimento (Eco-92), realizada no Rio de Janeiro, propiciou a intensificação do processo de ambientalização do Brasil, isto é, do processo 
de paulatina incorporação do paradigma do desenvolvimento sustentável no direito interno, nas instituições, nas políticas públicas, nos programas, planos, projetos e nas ações governamentais.

Além da Agenda $21 \mathrm{Global}$, outro importante documento elaborado durante a Eco-92 foi a Declaração do Rio de Janeiro sobre Meio Ambiente e Desenvolvimento (1992), que citou como relevantes à promoção de direitos humanos o respeito ao princípio da participação na gestão ambiental e ao princípio do acesso à informação ambiental, os quais foram posteriormente positivados no ordenamento jurídico brasileiro.

A Declaração do Rio de Janeiro influenciou a elaboração da Carta Mundial pelo direito à cidade (1992), documento declaratório redigido sobre três pilares básicos: direito à cidadania, gestão democrática e função social da propriedade e da cidade. Na Carta, o direito à cidadania é entendido como um direito à participação democrática de todos os habitantes de cidades, vilas e povoados na condução dos seus destinos, ou seja, direito de participar ativamente nos processos decisórios atinentes ao futuro da cidade.

A reivindicação cidadã pelo direito à cidade ganhou maior expressão durante as Conferências das Nações Unidas sobre Assentamentos Humanos, a partir das quais foi criado o Programa Habitat que reacendeu o debate sobre a necessidade de superação do modelo liberal de desenvolvimento, ao defender que a sustentabilidade em áreas urbanas pressupõe não apenas o desenvolvimento econômico compatível com a proteção do meio ambiente, mas também a realização de direitos sociais - direito à terra, à moradia, ao saneamento, à saúde, à educação, ao transporte público, à alimentação, ao trabalho e ao lazer - sem os quais não se pode falar em vida digna, tampouco em qualidade de vida.

Anos mais tarde, o Programa Habitat veio a ser complementado pela Declaração do Milênio, que fixou metas específicas para a promoção da sustentabilidade urbana no período de 2000 a 2015. A Agenda 2030, apresentada no final da Cúpula das Nações Unidas sobre o Desenvolvimento Sustentável (2015), realizada em Nova York, Estados Unidos, aditou a Declaração do Milênio para o período de 2016 a 2030. O documento é constituído por 169 metas e 17 objetivos globais voltados à realização do desenvolvimento sustentável, que ficaram conhecidos pela sigla "ODS".

Entre os objetivos delineados, destaca-se o de número 11, que visa tornar as cidades e os assentamentos humanos mais inclusivos, seguros, resilientes e sustentáveis. Para tanto, a agenda propõe, entre outras medidas, aumentar a urbanização inclusiva e sustentável; ampliar as capacidades para o planejamento e a gestão de assentamentos humanos participativos, integrados e sustentáveis e proporcionar o acesso universal a espaços públicos seguros, inclusivos e verdes (ONU, 2015). 
Em outubro de 2016, outra agenda foi criada no âmbito das Nações Unidas para tratar do tema do desenvolvimento sustentável. A Declaração de Quito, conhecida como a Nova Agenda Urbana, foi firmada no Equador durante a Conferência das Nações Unidas sobre Habitação e Desenvolvimento Urbano Sustentável (Habitat III) como sendo um compromisso político assumido pelos Estados-parte da ONU.

Com base na teoria de Lefèbvre (1968) e na Carta Mundial (1992), a Nova Agenda Urbana reconheceu o direito à cidade como um direito humano de produzir cidades e de viver em assentamentos justos, seguros, saudáveis, acessíveis, econômicos, resilientes e sustentáveis. Tratase de um direito difuso, de natureza prestacional, dotado de conteúdo axiológico e justiciabilidade que, para ter eficácia, demanda a realização de obrigações positivas por parte do Estado.

A Nova Agenda Urbana, documento de natureza soft law, sintetiza nos seus compromissos e princípios um conjunto histórico de reivindicações sociais por reforma urbana, as quais compreendem a luta pelo direito à cidade como conectada à luta pela promoção de direitos humanos. Revela uma compreensão ampla do direito à cidade (ALFONSIN, 2018, p. 123), convergindo com o sentido do direito à cidade sustentável positivado pelo Estatuto da Cidade, no Brasil, na medida em que conjuga em um só direito a função social da cidade e o direito de participação democrática em conexão com os direitos ambientais (BELLO; RIBEIRO, 2018, p. 148).

Como se pode perceber, ao longo do século XX e início do século XXI, a concepção de cidadania foi ampliada nos planos internacional e nacional, porém os desafios para a sua efetivação ainda são grandes, notadamente em tempos de retrocesso legislativo e desmonte dos mecanismos democráticos historicamente conquistados. Não à toa, a defesa dos direitos humanos e do meio ambiente em cidades exsurgem como prioridades convergentes na agenda internacional contemporânea, demandando cooperação internacional para fazer frente à complexidade das questões atuais (TRINDADE, 1993, p. 23).

Com efeito, o processo de internacionalização da proteção dos direitos humanos, a partir da Declaração Universal dos Direitos Humanos (1948), e da proteção do meio ambiente, alavancada pela Declaração de Estocolmo sobre Meio Ambiente Humano (1972), revelam a necessidade de tratamento sistêmico e proteção integral dos direitos civis, políticos, bem como dos direitos humanos econômicos, sociais, culturais e ambientais (DHESCA), direitos indivisíveis e interdependentes que geram obrigações de caráter objetivo (erga omnes) para os Estados-partes.

A compreensão holística dos direitos humanos ilumina um dos seus aspectos mais importantes: as obrigações decorrentes dos DHESCA podem ser positivas e negativas, sendo passíveis de atuação preventiva administrativa e judicial do Estado no âmbito da proteção do meio 
ambiente. As obrigações negativas dizem respeito à abstenção de determinadas atividades por parte do Estado, ao passo que as obrigações positivas comportam pelo menos três possibilidades: regulamentação para garantia do exercício de direitos, a exemplo do direito de acesso à informação; regulamentação para limitação ou restrição ao exercício de direitos e fornecimento de serviços à população (ABRAMOVICH, 2005, p. 198).

A proteção sistêmica dos direitos humanos, no atual contexto de busca pelo desenvolvimento sustentável enquanto discurso e movimento - que seja diversificado e descentralizado (RODRÍGUEZ-GARAVITO, 2014, p. 517) - perpassa por um contínuo exercício democrático nos processos de tomada de decisões em matéria urbanoambiental, o que pressupõe uma noção ampliada e fortalecida de cidadania, assim como o compartilhamento de responsabilidades entre Poder Público, mercado e sociedade para realização dos direitos fundamentais de acesso à informação, à justiça ambiental e de participação pública, inclusive mediante a mobilização de estratégias judiciais de litígio para defesa dos DHESCA (LANGFORD, 2009, p. 102).

Não obstante, há que se ter cautela para que a luta social pela efetivação dos direitos humanos não seja convertida em um messianismo político, por meio da imposição dos valores democráticos ocidentais justificadores de intervenções e ingerências em nome de um suposto bem comum da humanidade, pois democracia não é garantia da dignidade humana, tampouco o pluralismo político pode ser imposto pela força. A violência dos meios para afirmação dos valores democráticos invalidaria a nobreza dos fins pretendidos (TODOROV, 2012, p. 84).

Sendo assim, a participação pública para proteção de direitos humanos e do meio ambiente, seja na seara administrativa seja na esfera judicial, demanda a promoção do direito à informação e à educação ambiental, pois conhecimento é ferramenta que oferece condições de diálogo, formação de consenso e cooperação entre múltiplos atores sociais. Nessa linha de raciocínio, a Declaração do Rio de Janeiro (1992) citou o direito à informação em pelo menos três dos seus princípios (10, 18 e 19), ressaltando-o como a forma mais adequada de se garantir a participação dos cidadãos em decisões e políticas públicas ambientais.

A Declaração Universal dos Direitos Humanos de 1948 (artigos 19 e 21), o Pacto Internacional dos Direitos Civis e Políticos de 1966 (artigo 25), a Convenção Americana sobre Direitos Humanos de 1969 (artigo 23), a Declaração de Estocolmo de 1972 (princípios 19 e 20) e a Agenda 21 Global (capítulo 40) também trazem expressa referência à importância do amplo e livre acesso à informação e à participação pública na gestão ambiental, em áreas urbanas ou rurais, o que favorece 
um estremecimento da lógica de centralidade do poder decisório estatal, gerando sinergia com os valores encartados na Constituição da República de 1988 que fundamentam o Estado brasileiro.

Ainda no campo do Direito Internacional Público, a Convenção de Aarhus (1998) estabeleceu aos Estados-parte os tipos de informações e dados que devem ser postos à disposição da coletividade, independentemente de requerimento, como condição necessária à participação ativa em processos de tomada de decisões em planos, programas e políticas, bem como ao acesso à justiça e à coprodução de normas jurídicas que possam ter impacto sobre o meio ambiente e a qualidade de vida humana.

Em março de 2018, outro importante passo foi dado no sentido do fortalecimento da democracia urbana. Durante o término da 9a Reunião do Comitê de Negociação do Acordo Regional sobre o Princípio 10 da Declaração do Rio de Janeiro (1992), ocorrida em São José da Costa Rica, foi aprovado sob o status de documento vinculante o texto do Acordo Regional sobre Acesso à Informação, Participação Pública e Acesso à Justiça em assuntos ambientais na América Latina e no Caribe, que já conta com adesão e assinatura do Brasil.

O Acordo Regional, conhecido como Acordo de Escazú, significa um grande avanço político e um novo direcionamento para a efetivação de medidas internas que garantam direitos ambientais, em termos materiais e procedimentais, e que propiciem a construção de cidades mais justas, inclusivas, democráticas e sustentáveis na América Latina e no Caribe, com salvaguarda dos direitos humanos. Seus princípios sobre a relação entre desenvolvimento e meio ambiente harmonizam-se com os Objetivos do Desenvolvimento Sustentável e com a Agenda 2030, estabelecendo critérios para aplicação do Princípio 10 da Declaração do Rio de Janeiro no âmbito da região latino-americana e caribenha.

\footnotetext{
Os mecanismos de controle e participação da sociedade proporcionados por tais direitos ou posições jurídicas subjetivas derivados dos direitos ambientais procedimentais configuram importante instrumento a serviço dos indivíduos e das entidades associativas protetoras do ambiente para exigir o estrito cumprimento da legislação ambiental por parte de agentes públicos e privados (SARLET; FENSTERSEIFER, 2018, p. 421).
}

Os diversos eventos jurídico-políticos e documentos internacionais trazidos à lume nesta seção demonstram, em resumo, como ao longo do tempo foram se entrelaçando os movimentos por proteção dos direitos humanos e do meio ambiente em áreas urbanas, relevando que, na contemporaneidade, a luta é comum e precisa ser fortalecida sob novas bases democráticas. 
3 Reflexões sobre democracia participativa em matéria urbanoambiental, à luz da Constituição da República de 1988 e do Estatuto da Cidade

A Constituição da República de 1988 representa um marco no processo de democratização do Brasil que, de forma inédita na sua história legislativa, criou um sólido arcabouço jurídico voltado à proteção ambiental, fortalecendo a atuação do Poder Público em todos os níveis federativos e a participação da coletividade em seus deveres solidários e comuns, como se pode abstrair de leitura dos artigos 5, XXII e XXIII; 21, XX; 23, VI e VII; 30, VIII e IX; 170, III, VI; 182; 183; 200, VIII, 215, 216 e 225.

Na perspectiva constitucional, a participação democrática não ocorre apenas indiretamente, por meio de representação política, mas pode ser protagonizada de forma direta pela população, atribuindo assim legitimidade à práxis e deliberações legislativas e administrativas afetas à matéria urbanoambiental (SARLET; FENSTERSEIFER, 2014, p. 50).

Nesse sentido, a democracia participativa encontra-se conectada à dignidade da pessoa humana e aos direitos fundamentais dela decorrentes por um elo que é a cidadania, a qual não se exaure no voto, nem se resume ao exercício da democracia direta nas figuras do plebiscito, do referendo e da iniciativa legislativa popular (BONAVIDES, 2001, p. 28).

Um conjunto de propostas tendentes a aumentar o grau de participação dos cidadãos na vida pública, pela abertura de novos canais que complementem as instituições representativas tradicionais. As virtudes dessas novas formas de participação estariam não apenas na ampliação das possibilidades de articulação de interesses e opiniões, mas também por propiciarem sua maior reflexão e a aproximação de posições diferentes. Basicamente, podemos dividi-las em dois campos:

a) propostas tendentes a ampliar as esferas de consulta e deliberação dos cidadãos em questões públicas, tanto por institutos de democracia direta quanto pela criação de fóruns em que os cidadãos representam os demais em matérias específicas;

b) propostas tendentes a ampliar a participação de associações representativas dos cidadãos na elaboração, gestão e controle das políticas públicas.

Tais propostas implicam mudanças na distribuição primária de recursos de poder entre governantes e governados, especialmente quando tornam exclusivas da cidadania a tomada de decisões políticas que não se restringem à eleição de representantes (MAUÉS, 1999, p. 123).

Ao discutir os dilemas da democracia participativa, Maués (1999, p. 124-125) assevera que, apesar da inovação trazida pela Constituição da República de 1988, a qual contempla características de democracia direta e representativa (forma mista) - como se pode verificar nos artigos 1ㅇ, $\$ 1$; ; 
14; 194, VII; 198, I, III; 204, I, II; 206, VI; 227, §70 - os institutos democráticos nela previstos ainda são basicamente de matriz liberal-representativa.

Por outro lado, as disposições constitucionais possibilitam uma ampliação das formas de participação cidadã, o que pode propiciar um fortalecimento dos seus poderes normativos, a depender da forma como os critérios democráticos serão regulamentados pela legislação infraconstitucional.

Este argumento é relevante para a superação das limitações escalares e procedimentais inerentes ao exercício da participação direta (por meio dos cidadãos e das associações), que deve garantir a igualdade política e a liberdade de participação, indo além, portanto, da democracia liberal-representativa no Estado contemporâneo. O desafio da participação direta no processo de tomada de decisões políticas é complexo, porque demanda engajamento, fomento e preparação ao exercício democrático antes mesmo da etapa decisória, o que pressupõe distribuição de recursos políticos para a cidadania.

Igualdade e participação conjugam-se como requisitos ao pleno exercício de outros direitos, os quais, em contrapartida, são imprescindíveis ao regular funcionamento do processo democrático, como é o caso do direito de acesso à informação (PAUTASSI, 2010, p. 65).

Nesta linha de raciocínio, o artigo 21, XX, da Carta Magna dispõe que compete à União instituir diretrizes para o desenvolvimento urbano, ao passo que o artigo 182 estabelece que a política de desenvolvimento urbano deve ser executada pelo Poder Público municipal, de acordo com as diretrizes gerais fixadas por lei federal, para o fim de ordenar o pleno desenvolvimento das funções sociais da cidade e garantir o bem-estar de seus habitantes. O artigo 225 da Constituição, por seu turno, assegura o direito fundamental ao meio ambiente, impondo ao Poder Público e à coletividade o dever de defendê-lo e preserva-lo para as atuais e futuras gerações.

O meio ambiente é considerado um macro bem que pertence às presentes e futuras gerações e que não pode ser tratado de forma fragmentada, mas sim de maneira holística, preservando a unidade axiológico-normativa do texto constitucional, do qual emerge a síntese socioambiental (SANTILLI, 2005, p. 92). A consequência dessa visão holística é uma ressignificação do direito de propriedade provocada por releitura do artigo 170 da Carta Magna: o possuidor ou proprietário, seja ele público, seja particular, não pode dispor da qualidade do meio ambiente, considerado bem de uso comum do povo, de natureza jurídica difusa (LEITE, 2015, p. 174-175).

A solidariedade intergeracional busca amparo em condutas colaborativas que visam a realização do bem-estar social e a proteção do meio ambiente, inclusive na esfera judicial, por meio 
do exercício da cidadania participativa. A cooperação está intrinsecamente ligada à participação, formando duas faces da mesma moeda (LEITE, 2015, p. 204).

A Lei n. 10.257/2001 (Estatuto da Cidade), ao regulamentar os artigos 182 e 183 da Constituição de 1988, fixou normas de ordem pública e interesse social sobre o uso e a ocupação do solo urbano para realização de igualdade, cidadania e melhoria da qualidade de vida humana. As limitações urbanísticas visam promover a realização da função social da propriedade e da cidade, o bem-estar humano e o equilíbrio ambiental, para efetivação do direito à cidade justa, democrática e sustentável.

Os instrumentos urbanísticos previstos no Estatuto da Cidade cumprem o papel de induzir e regrar as formas de uso e ocupação do solo urbano, enquanto a gestão democrática se encarrega de assegurar a participação cidadã nos processos de planejamento e tomada de decisões sobre assuntos relativos ao futuro da cidade (ROLNIK, 2001, p. 5).

O artigo 2o da Lei n. 10.257/2001 contém diretrizes gerais que devem orientar o Brasil na concretização da sustentabilidade urbana, entre elas as diretrizes sociais que asseguram o direito à cidade sustentável, entendido como aquele que se materializa por meio da realização do direito à terra urbana, à moradia, ao saneamento ambiental, à infraestrutura urbana, ao transporte e aos serviços públicos, ao trabalho e ao lazer.

As diretrizes sociais visam promover um benefício à coletividade, por isso admitem a participação da comunidade no processo de planejamento da cidade, mediante gestão democrática que assegure a participação de múltiplos os atores sociais no planejamento, na execução e no monitoramento de planos, programas e projetos de desenvolvimento urbano (CARVALHO FILHO, 2013, p. 30), partindo da convicção de que a comunidade presenta potencial para cogerir o seu destino (DEMO, 2001, p. 60).

Apesar do avanço espelhado na concepção ampliada de participação pública, verifica-se que um dos maiores desafios à realização da democracia nos espaços urbanos não reside na simples ampliação do envolvimento popular durante uma audiência pública. Reside sim na promoção de democracia para que todos, inclusive as camadas mais desfavorecidas da sociedade, tenham liberdade e acesso em igualdade de condições aos mecanismos participativos nos processos decisórios, porque isso pressupõe democratização da Administração Pública, descentralização de estruturas organizacionais do Estado e uma profunda mudança nas relações de poder (DIAS, 2011, p. 321).

Não se pode falar em abertura democrática sem a possibilidade de inclusão de diversos grupos populacionais diretamente atingidos por uma obra, empreendimento ou atividade efetiva ou 
potencialmente capaz de causar impactos socioeconômicos e ambientais. No campo da política urbana, a vivência da cidadania pressupõe a prática política (DIAS, 2011, p. 309), por isso a democracia participativa, em sentido material e procedimental, deve expressar relações socioespaciais que podem ser afetadas por um projeto urbanoambiental.

A audiência da população nestes casos configura, a um só tempo, dever jurídico do Poder Público e direito dos habitantes da cidade. Para garantir o controle social de políticas públicas e o pleno exercício da cidadania em direção ao desenvolvimento urbano previsto no artigo $21, \mathrm{XX}$, da Carta Magna, o artigo 45 da Lei n. 10.257/2001 determina, em complementação ao disposto no artigo $2^{\circ}$, que os gestores incluam, obrigatoriamente, a participação da população e de associações civis representativas das comunidades no processo de gestão democrática da cidade.

Somente por meio do exercício democrático permanente é que se estará materializando o comando contido no artigo 225 da Constituição de 1988 (SARLET; FENSTERSEIFER, 2014, p. 53). Trata-se de condição de legitimidade das práticas e decisões administrativas em questões urbanoambientais, uma vez que as decisões do Poder Público precisam convergir com a vontade coletiva, sem fazer uso meramente formal dos instrumentos ambientais e urbanísticos. Bercovici (2004, p. 69), ao discorrer sobre os dilemas do Estado Federal de Direito e sobre a necessidade de planejamento e coordenação na descentralização de políticas públicas, esclarece que:

O debate não deve ser entre descentralização e centralização, mas qual descentralização e para que (e para quem) descentralizar. [...] A descentralização deve ser realizada de maneira articulada, não conflitiva, como vem ocorrendo. O desequilíbrio gerado na descentralização é solucionado com uma política planejada de cooperação e coordenação entre União e entes federados, com os objetivos do desenvolvimento e da promoção da igualação das condições sociais de vida [...].

No que diz respeito às políticas urbanas, caso no processo de elaboração do Plano Diretor e na fiscalização de sua implementação para tornar efetiva a gestão democrática e transparente da cidade os Poderes Executivo e Legislativo municipais não cumpram os deveres elencados no artigo 40, §4으, I a III, do Estatuto da Cidade - a exemplo de promoção de audiências públicas e de debates com a participação da população e de associações representativas dos vários segmentos da comunidade; publicidade quanto aos documentos e informações produzidos e acesso de qualquer interessado aos documentos e informações públicos produzidos - os responsáveis pelo impedimento ou pela omissão ficarão sujeitos a responder por atos de improbidade administrativa (MEIRELLES, 2014, p. 557).

Para garantir a gestão democrática da cidade em direção ao desenvolvimento sustentável, sob uma perspectiva multiescalar, a Lei n. 10.257/2001 enumera no seu artigo 43 quatro 
instrumentos básicos: órgãos colegiados de política urbana, nos níveis nacional, estadual e municipal; debates, audiências e consultas públicas; conferências sobre assuntos de interesse urbano, nos níveis nacional, estadual e municipal; e iniciativa popular de projeto de lei e de planos, programas e projetos de desenvolvimento urbano. A lista de instrumentos não é exaustiva, de maneira que outros podem ser criados para aperfeiçoar o planejamento e a gestão urbanos, tais como aqueles elencados no artigo subsequente, os quais são voltados à promoção de responsabilidade fiscal na gestão orçamentária municipal.

No artigo 44 da Lei n. 10.257/2001, a participação cidadã emerge como princípio e regra jurídica que deve guiar debates, audiências e consultas públicas sobre as propostas do plano plurianual, da lei de diretrizes orçamentárias e do orçamento anual. Assim como as cidades, os organismos gestores das regiões metropolitanas e aglomerações urbanas também devem incluir a participação da população e de associações representativas dos vários segmentos da comunidade no controle direto de suas atividades, para pleno exercício da cidadania.

O que se pode inferir a partir da análise da Lei n. 10.257/2001 é que a realização do projeto da cidade sustentável depende não somente de um exercício permanente da democracia na gestão urbana, mas também uma reengenharia institucional e um agir segundo a ética do desenvolvimento sustentável.

Pela inspiração política da Carta Magna, que se afina com as diretrizes sociais presentes no Estatuto da Cidade, constata-se que a democracia participativa, enquanto conquista política e resultado de lutas sociais, significa, ao mesmo tempo, meio e fim de autopromoção para a efetivação do direito ao meio ambiente e ao desenvolvimento urbano sustentável. Esse reconhecimento, no entanto, exige a criação de instituições de inovação cívica para exercício de uma cidadania ativa e de corresponsabilidade social entre Poder Público, sociedade e mercado, que venha ao encontro do direito-dever emanado dos artigos 182 e 225 da Constituição da República de 1988.

Participação é direito e metodologia, uma conquista cidadã na história dos direitos humanos e do Brasil republicano, que implica na necessidade de contínua prática política, por meio da negociação de conflitos e divergências, para além da decisão tomada por uma maioria de votantes. Isso, por sua vez, pressupõe abertura para o diálogo e para a tomada de decisões coletivas, sem coerção, a fim de que a deliberação pública, especialmente a práxis em matéria urbanoambiental, reflita de fato os anseios da comunidade e esteja de acordo com os fundamentos democráticos da Constituição de 1988.

Assim, convém esclarecer que espécie de participação encontra respaldo constitucional e no Estatuto da Cidade, visto que os processos participativos podem ser classificados em pelo menos 
nove níveis de análise, que vão desde a ausência total até a autogestão, passando pelos graus da participação passiva, informativa, consultiva, com consulta obrigatória, propositiva, cogestão e delegação (SILVA, 2003, p. 302-303).

Os níveis de análise da participação servem para demonstrar que existem diversas formas de participação política, mas nem todas configuram uma experiência capaz de promover inovação nos processos de planejamento e gestão de políticas públicas urbano-ambientais. Para que a sociedade brasileira avance e promova cidadania é necessário persistir na criação e implantação de condições institucionais favoráveis à participação ativa e, ao mesmo tempo, investir na educação política voltada ao amadurecimento dos ideais democráticos e dos seus mecanismos de controle social (ROCHA; SPANIOL; SCHOMMER; SOUSA, 2012, p. 14).

Por esse viés, a criação de novos espaços públicos de planejamento, cogestão e tomada de decisão coletiva constitui mais do que uma proposta teórico-metodológica inovadora, sendo sim uma demanda cívica necessária ao desenvolvimento do território, o que exige maior empenho dos atores locais, já que estão mais próximos dos problemas urbanoambientais que desafiam cotidianamente o projeto político da sustentabilidade.

A delimitação do conteúdo essencial e do alcance do direito à participação pública em matéria urbanoambiental é tão desafiadora quanto a avaliação da sua efetividade, pois o ordenamento jurídico brasileiro não contém positivados critérios metodológicos de análise, sendo este, portanto, um campo fértil para futuras pesquisas.

A importância da avaliação reside na justiciabilidade dos direitos humanos e das políticas públicas urbanoambientais, o que inclui a possibilidade de discussão judicial sobre a realização ou negação do direito à participação pública enquanto meio e fim, isto é, direito material e direito procedimental. Interessa, pois, estabelecer e regulamentar quais elementos objetivos devem ser aplicados para análise concreta, a fim de se exigir do Estado alguma providência. Eis outro grande passo que precisa ser dado em direção à efetivação do direito à participação pública, seja na esfera administrativa, seja no campo judicial.

\section{Considerações Finais}

A pesquisa revelou que, embora a trajetória da cidadania política no Brasil tenha sido marcada por forte exclusão e apesar dos avanços ocorridos nos planos nacional e internacional para proteção dos direitos humanos e do meio ambiente, a realização do direito à cidade e dos princípios 
constitucionais que orientam as Políticas Urbana e Ambiental no Brasil depende da renovação de um compromisso com o aprofundamento da democracia.

As conquistas sociais encartadas na Lei n. 10.257/2001 exigem enfrentamento cotidiano das assimetrias de poder econômico e político que se superpõem sobre os territórios, produzindo e acentuando injustiça social e insustentabilidade urbana pela desfiguração do direito à proteção do meio ambiente e pela neutralização da gestão democrática da cidade.

Sendo assim, em termos teóricos, a efetividade do direito à participação pública depende de uma refundação democrática do Estado de Direito e, ainda, de uma profunda mudança nas relações de poder que interferem nos processos de tomada de decisões em matéria urbanoambiental. caminho perpassa, sem dúvida, por um necessário amadurecimento dos ideais democráticos, pelo fortalecimento dos mecanismos institucionais de controle social e pela criação de medidas inovadoras para ampliar o exercício dos direitos fundamentais à informação e à participação pública.

Tendo em vista a superação do desafio ora identificado, sugere-se uma ampliação dos debates sobre o direito à participação pública em assuntos urbanoambientais e, ainda, a regulamentação do procedimento participativo por meio da construção de fluxos e critérios metodológicos que permitam uma avaliação adequada da efetividade do direito. A definição de elementos objetivos de análise é relevante porque a desconformidade do procedimento participativo com os fundamentos materiais que decorrem das normas adotadas pelo Brasil deve ser passível de controle social, de invocação e reconhecimento in concreto pelo Poder Público, nas esferas administrativa e judicial.

Indica-se, desse modo, a necessidade de estudos empíricos e jurisprudenciais subsequentes para verificação das questões dogmáticas revisitadas neste artigo, que apontem as limitações e os desafios experimentados por múltiplos agentes sociais para a realização do direito à participação pública na proteção do meio ambiente e na gestão de cidades.

\section{Notas}

10 presente trabalho foi realizado com apoio da Coordenação de Aperfeiçoamento de Pessoal de Nível Superior - Brasil (CAPES) - Código de Financiamento 001.

2 This study was financed in part by the Coordenação de Aperfeiçoamento de Pessoal de Nível Superior - Brasil (CAPES) - Finance Code 001.

\section{Referências}


ABRAMOVICH, Victor E. Linhas de trabalho em direitos econômicos, sociais e culturais: instrumentos e aliados. In: SUR - Revista Internacional de Direitos Humanos, São Paulo, Ano 2, n. 2, p. 188-223, 2005. Disponível em: <http://www.dhnet.org.br/dados/revistas/sur/revista_sur_02.pdf >. Acesso em: 20 mar. 2018.

ALFONSIN, Betânia. Repercussões da Nova Agenda Urbana no Direito Público e Privado no Brasil e na América Latina: o papel do direito à cidade. In: BELLO, Enzo; KELLER, Rene José. Curso de Direito à Cidade - teoria e prática. Rio de Janeiro: Lumen Juris, 2018, p. 119-132.

BELLO, Enzo; RIBEIRO, Mariana Dias. O direito à cidade e os novos direitos urbanos como direitos humanos e direitos fundamentais. In: BELLO, Enzo; KELLER, Rene José. Curso de Direito à Cidade teoria e prática. Rio de Janeiro: Lumen Juris, 2018, p. 133-154.

BERCOVICl, Gilberto. Dilemas do Estado Federal Brasileiro. Porto Alegre: Livraria do Advogado, 2004.

BONAVIDES, Paulo. Teoria constitucional da democracia participativa. São Paulo: Malheiros, 2001.

CARVALHO FILHO, José dos Santos. Comentários ao Estatuto da Cidade. 5. ed. São Paulo: Atlas, 2013.

CARVALHO, José Murilo de. Cidadania no Brasil: o longo caminho. 18. ed. Rio de Janeiro: Civilização Brasileira, 2014.

DEMO, Pedro. Participação é conquista. 5. ed. São: Cortez, 2001.

DIAS, Daniella Maria dos Santos. Democracia urbana. 1. ed. 1a reimpr. Curitiba: Juruá: 2011.

FÓRUM SOCIAL MUNDIAL. Carta Mundial pelo Direito à Cidade. Porto Alegre, 2005. Disponível em: <http://normativos.confea.org.br/downloads/anexo/1108-10.pdf>. Acesso em: 20 mar. 2018.

HOLSTON, James. Cidadania insurgente: disjunções da democracia e da modernidade no Brasil. São Paulo: Companhia das Letras, 2013. 
LANGFORD, Malcolm. Judicialização dos direitos econômicos, sociais e culturais no âmbito nacional: uma análise socio-jurídica. In: SUR - Revista Internacional de Direitos Humanos, n. 11, p. 99-133, 2009. Disponível em: <www.conectas.org/pt/acoes/sur/edicao/11>. Acesso em: 20 mar. 2018.

LEITE, José Rubens Morato. Sociedade de Risco e Estado. In: CANOTILHO, José Joaquim Gomes; LEITE, José Rubens Morato (Orgs.). Direito constitucional ambiental brasileiro. 6. ed. rev. São Paulo: Saraiva, 2015, p. 157-242.

MAÚES, Antonio Gomes Moreira. Poder e democracia: o pluralismo político na Constituição de 1988. Porto Alegre: Síntese, 1999.

MEIRELLES, Hely Lopes. Direito Municipal Brasileiro. 17. ed. São Paulo: Malheiros, 2014.

ORGANIZAÇÃO DAS NAÇÕES UNIDAS - ONU. Conheça os novos objetivos de desenvolvimento sustentável. 2015. Disponível em:

<http://www.unmultimedia.org/radio/portuguese/conheca-os-novos-objetivos-dedesenvolvimento-sustentavel/>. Acesso em: 20 mar. 2018.

PAUTASSI, Laura. Indicadores en materia de derechos económicos, sociales y culturales. Más allá de la medición. In: ABRAMOVICH, Víctor; PAUTASSI, Laura. La medición de derechos em las políticas sociales. 1. ed. Ciudad Autónoma de Buenos Aires: Del Puerto, 2010, p. 1-87.

ROCHA, Arlindo Carvalho; Spaniol, Enio Luiz. SCHOMMER, Paula Chies; SOUSA, Alessandra Debone de. A coprodução do controle como bem público essencial à accountability. In: Anais do XXXVI Encontro da ANPAD - ENANPAD, Rio de Janeiro, 2012. Disponível em: <http://www.anpad.org.br/admin/pdf/2012_APB556.pdf>. Acesso em: 20 mar. 2018.

RODRÍGUEZ-GARAVITO, César. O futuro dos direitos humanos: do controle à simbiose. In: SUR Revista Internacional de Direitos Humanos, v. 11, n. 20, p. 515-526, jun-dez/2014. Disponível em: <www.conectas.org/pt/acoes/sur/edicao/20>. Acesso em: 20 mar. 2018. 
ROLNIK, Raquel. Estatuto da Cidade: Instrumento para as cidades que sonham crescer com justiça e beleza. In: SAULE JÚNIOR, Nelson; ROLNIK, Raquel (Orgs.). Estatuto da Cidade: novos horizontes para a reforma urbana. São Paulo, Pólis, Cadernos Pólis, n. 4, p. 5-9, 2001.

SANTOS, Boaventura de Sousa; CHAUI, Marilena. Direitos humanos, democracia e desenvolvimento. São Paulo: Cortez, 2013.

SILVA, Tarcísio. Da participação que temos à participação que queremos: o processo do OP na cidade de Recife. In: AVRITZER, Leonardo; NAVARRO, Zander (Orgs.). A inovação democrática no Brasil. São Paulo: Cortez, 2003, p. 297-334.

SANTILLI, Juliana. Socioambientalismo e novos direitos: proteção jurídica à diversidade biológica e cultural. São Paulo: Peirópolis, 2005.

SARLET, Ingo Wolfgang; FENSTERSEIFER, Tiago. Democracia participativa e participação pública como princípios do Estado Socioambiental de Direito. In: Revista de Direito Ambiental, ano 19, v. 73, jan./mar., 2014, p. 47-90.

. Princípios do Direito Ambiental. 2. ed. São Paulo: Saraiva, 2017.

. Direitos ambientais procedimentais: acesso à informação, à participação pública na tomada de decisão e acesso à justiça em matéria ambiental. In: Revista Novos Estudos Jurídicos, v. 23, n. 2, 2018, p. 417-465.

TODOROV, Tzvetan. Os inimigos íntimos da democracia. São Paulo: Companhia das Letras, 2012.

TRINDADE, Antônio Augusto Cançado. Direitos humanos e meio ambiente: paralelo dos sistemas de proteção internacional. Porto Alegre: Sergio Antonio Fabris Editor, 1993.

Trabalho recebido em 13 de janeiro de 2019

Aceito em 24 de fevereiro de 2019 